\title{
STUDI AWAL DESAIN SISTEM INJEKSI AEROSOL PADA PENGEMBANGAN FASILITAS EKSPERIMEN PENGUNGKUNG CONTAINMENT (FESPeCo Mod.1)
}

\author{
Arif Adtyas Budiman ${ }^{1}$, Almira Citra ${ }^{1}$, Joko P. W ${ }^{1}$ \\ ${ }^{1}$ Pusat Teknologi dan Keselamatan Reaktor Nuklir, Gd .80 Kawasan Puspiptek Serpong, \\ Tangerang Selatan, 15310, Indonesia \\ email:arif-adtyas@batan.go.id
}

\begin{abstract}
ABSTRAK
STUDI AWAL DESAIN SISTEM INJEKSI AEROSOL PADA PENGEMBANGAN FASILITAS EKSPERIMEN PENGUNGKUNG CONTAINMENT (FESPeCo Mod.1).

Salah satu skenario kecelakaan reaktor nuklir berpendingin air ringan yaitu adanya lepasan zat radioaktif akibat terjadinya kebocoran sistem pemipaan primer. Simulasi kecelakaan dengan skenario tersebut dapat dilakukan menggunakan Fasilitas Eksperimen Simulasi Pendingin Containment (FESPeCo). Untuk memenuhi kebutuhan penelitan saat ini, revitalisasi FESPeCo dilakukan dengan menambahkan sistem injeksi aerosol menjadi FESPeCo Mod.1. Sistem injeksi aerosol terdiri dari unit kompressor, pengaduk, dan pengatur aliran fluida. Penelitian ini bertujuan untuk mendapatkan kandidat desain tabung aerosolsebelum dilakukan fabrikasi. Metode Computational Fluid Dynamic (CFD) digunakan sebagai perangkat utama analisis dinamika fluida.. Untuk melihat pengaruh dinamika fluida terhadap bentuk geometri, variasi tekanan operasi diberikan pada keempat model diantaranya TAB 01, TAB 02, TAB 03, dan TAB 04. Berdasarkan hasil analisis terhadap keempat model tersebut, bentuk geometri ruang silinder memegang peranan penting dalam pengadukan. Selain itu, perbedaan ukuran inlet dan outlet dapat mempengaruhi kuantitas keluaran aerosol yang signifikan,ditinjau dari besar kecepatan aliran dan beda tekanannya. Oleh karena itu, model TAB 04 dapat direkomendasikan sebagai kandidat utama tabung aerosol bertekanan pada sistem injeksi aerosol.
\end{abstract}

Kata kunci : Aerosol, Sistem Injeksi Aerosol, Laju Aliran, Beda Tekanan, FESPeCo Mod.1.

\begin{abstract}
PRELIMINARY STUDY OF AEROSOL INJECTION SYSTEM DESIGN IN THE DEVELOPMENT OF FASILITAS EKSPERIMEN PENGUNGKUNG CONTAINMENT (FESPeCo Mod.1). One of the light water-cooled nuclear reactor accident scenarios is the release of radioactive substances due to leakage of the primary piping system. Accident simulations with these scenarios can be performed using the Containment Coolant Simulation Experiment Facility (FESPeCo). To meet current research needs, the revitalization of FESPeCo is done by adding an aerosol injection system to FESPeCo Mod. 1. The aerosol injection system consists of a compressor, stirrer and flow control unit. The aim of this study is to obtain a design candidate for aerosol tubes before fabrication. The Computational Fluid Dynamic (CFD) method is used as the main tool for fluid dynamics analysis. To see the effect of fluid dynamics on geometric shapes, variations in operating pressure are given in all four models, i.e. $T A B$ 01, TAB 02, TAB 03, and TAB 04. According on the results of the analysis of the four models, the geometrical shape of the cylinder chamber plays an important role in stirring. In addition, differences in inlet and outlet sizes can significantly influence the quantity of aerosol output, in terms of flow velocity and pressure difference. Therefore, the TAB 04 model can be recommended as a main candidate for aerosol tubes of the aerosol injection system
\end{abstract}

Keywords: Aerosol, Aerosol Injection System, Flowrate, Pressure Drop, FESPeCo Mod.1 


\section{PENDAHULUAN}

Sistem utama keselamatan fasilitas Pembangkit Listrik Tenaga Nuklir (PLTN) menggunakan prinsip defense in depth atau pertahanan berlapis, yaitu dimulai dari sistem pembungkus bahan bakar, pengungkung radiasi dan hamburan radionuklida yang berada di dalam ruang gedung reaktor nuklir (containment $)^{[1]}$. Sistem pemipaan untai primer tipe Pressurize Water Reactor (PWR) terpisah dengan sistem sekunder, berbeda dengan tipe Boiling Water Reactor (BWR).Namun, sistem untai primer keduanya tetap berada di dalam containment. Potensi terjadinya lepasan material fisi pada untai primer pada PLTN jenis reaktor air ringan dapat terjadi jika terjadi pelelehan bahan bakar dan terbawa bersama aliran di untai primer yang mengalami kebocoran ${ }^{[2]}$. Salah satu produk fisi yang ditemukan lepas ke lingkungan pasca kejadian Fukushima Daiichi yaitu C11, dengan ukuran diameter rata-rata sekitar $70 \mu \mathrm{m}{ }^{[3]}$. Sistem mitigasi lepasan produk fisi merupakan salah satu sistem keselamatan aktif. Pada dasarnya, sistem ini membutuhkan pasokan daya listrik. Pelepasan sejumlah air dalam laju alir tertentu dari bagian atas containment telah diterapkan pada desain reaktor tipe air ringan ${ }^{[4]}$.

Pengkajian lebih mendalam dengan skenario hamburan yang menyerupai karakteristik produk fisi secara non nuklir dapat dilakukan menggunakan Fasilitas Eksperimen Simulasi Pendinginan Pada Containment (FESPeCo). Beberapa penelitian dengan skenario kehilangan aliran pendingin disebut sebagai Loss of Coolant Accident (LOCA) disimulasikan dengan adanya lepasan uap air dari sistem pemipaan ke dalam gedung reaktor pernah dilakukan menggunakan FESPeCo pada satu dekade terakhir ${ }^{[5,6]}$. Parameter yang diukur yaitu suhu, laju alir fluida dan tekanan uap pada titik-titik ketinggian tertentu. Untuk mendapatkan bentuk simulasi yang mendekati sebenarnya, pengembangan FESPeCo menjadi FESPeCo Mod.1 mulai dilakukan dengan menambahkan unsur padatan yang disebut sebagai aerosol. Aerosol merupakan perwujudan dari adanya bahan hasil fisi yang ikut serta lepas ke udara di dalam containment reaktor nuklir. Simulasi ini pernah dilakukan oleh Mohler, dkk. menggunakan fasilitas Aerosol Interactions and Dynamics in the Atmosphere (AIDA) di mana lokasi aerosol generator berada di bagian ruang atasnya. Lain halnya dengan FESPeCo, yang memiliki inlet injeksi aerosol berada di bagian bawah. Justifikasi posisi aerosol FESPeCo ditentukan dari model sistem injeksi aerosol yang menggunakan kompresor.

Tujuan penelitian ini yaitu untuk menentukan desain sistem injeksi aerosol 
yang sesuai untuk FESPeCo. Prinsip utama desain sistem injeksi aerosol yaitu keluaran distribusi aerosol yang homogen dan mudah dalam perawatan unit. Metode analisis dengan pendekatan Computational Fluid Dynamics (CFD). Penggunaan metode CFD telah banyak digunakan dalam analisis dinamika aliran. Salah satunya yaitu, Geraldini, P. dalam penelitiannya mengenai distribusi partikel di udara pada daerah kerja menggunakan metode CFD. Geraldini membahas pola distribusi partikel menggunakan pemodelan 3D dari perangkat lunak COMSOL Multiphysics ${ }^{\circledR}$. Simulasi dari pemodelan ruang kerja kemudian dibandingkan dengan data hasil pengukuran dari Continuous Air Monitoring (CAM), sehingga dapat disimpulkan bahwa terdapat kesesuaian antara hasil simulasi dan data lapangan [7]. Selain itu, A.K. Dwivedi, dkk, dalam penelitiannya terkait distribusi aerosol yang berada di dalam sistem untai primer reaktor nuklir pada saat kecelakaan menggunakan pendekatan analisis CFD yang divalidasi oleh hasil eksperimen dari National Aerosol Test Facility (NATF) di Bhaba Atomic Research Center (BARC) [8].

Desain sistem injeksi aerosol terdiri dari perangkat kompressor, pengaduk dan pengatur aliran fluida. Pengaduk dan pengatur aliran fluida disebut sebagai tabung aerosol bertekanan (TAB). Pada penelitian ini, untuk memperoleh desain $\mathrm{TAB}$ yang optimal, variasi tekanan operasi dilakukan dan disimulasikan dalam kondisi tunak menggunakan perangkat CFD (FLUENT).

\section{TEORI}

Pemodelan dan simulasi 3D melibatkan unsur ruang dalam koordinat $\mathrm{x}, \mathrm{y}$, dan $\mathrm{z}$. Batasan kondisi ini mengaktifkan fungsi radial equilibrium distribution pressure pada batasan kondisi pressure inlet dan outlet. Penentuan parameter tekanan total (total pressure) pada batasan kondisi pemodelan pressure inlet mengikuti persamaan sebagai berikut ${ }^{[9]}$;

$$
p_{0}=p_{s}\left(1+\frac{\gamma-1}{2} M^{2}\right)^{\gamma /(\gamma-1)}
$$

\section{$\underline{\text { Keterangan ; }}$}

$\gamma=$ perbandingan kapasitas panas $\left(C_{p} / C_{v}\right)$,

$\mathrm{M}=$ Bilangan Mach,

$p_{s}=$ tekanan statik (bar),

$p_{0}=$ tekanan total (bar).

Sedangka pada area keluaran (outlet), fungsi radial equilibrium distribution pressure digunakan dikarenakan adanya kemungkinan fenomena fisis berupa twisted air atau pola berpilin/pencampuran pada semua model. Fungsi tersebut diekspresikan dalam persamaan berikut [9];

$$
\frac{d p}{d r}=\frac{\rho v_{\theta}^{3}}{r}
$$

dengan $r$ merupakan jarak dari pusat putarandan $v_{\theta}$ adalah kecepatan tangensial.

Distribusi aerosol dideskripsikan melalui pola aliran fluida di dalam TAB. 
Udara dimampatkan pada nilai tertentu oleh kompressor dan dilepaskan ke dalam TAB dengan tujuan untuk mengaduk aerosol dan mengendalikan aliran fluida saat memasuki ruang FESPeCo Mod.1. Gambar 1 menunjukkan untai FESPeCo Mod.1 yang memiliki konfigurasi injeksi uap (No.2) dan aerosol (No.1).

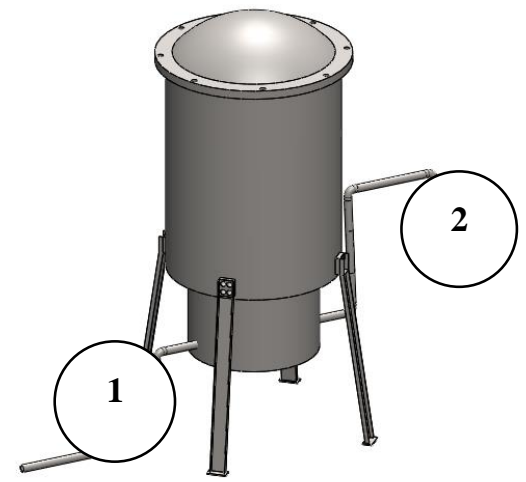

Gambar 1. Draft desain Untai FESPeCo Mod.1.

Pada Gambar 1, terdapat dua unit pemasok produk fisi yang dimodelkan dalam bentuk sistem pembangkit uap (sedang dalam proses desain dan uji fungsi No. 2) dan sistem injeksi aeorosol (No. 1). Kedua sistem saat ini masih memiliki kendali yang terpisah, namun tidak menutup kemungkinan untuk dapat dikendalikan ke dalam satu bentuk program pengendalian pemanas dan katup melalui sistem data akuisisi dan kendali .

Konfigurasi sistem injeksi aerosol yang bersifat tetap dalam penelitian ini yaitu kompresor, sedangkan perangkat dan pengatur aliran fluida dibuat dengan memperhatikan pertimbangan teknis. Sifat keseragaman dari pancaran aerosol yang diinjeksikan dapat diterjemahkan ke dalam pola aliran fluida terhadap bentuk geometri dan metode pengaturannya. Prinsip dasar pemodelan TAB yaitu kemudahan dalam pengoperasian dan perawatan, mengingat beberapa kandidat aerosol yang akan digunakan diantaranya bersifat higroskopis. Untuk memenuhi hal tersebut, optimalisasi bentuk geometri (tanpa menggunakan pengaduk bermotor), dan penggunaan material tembus pandang kemudian dipilih.

Konsep desain dibuat dengan mempertimbangkan tingkat kemudahan fabrikasi. Gambar 2 merupakan beberapa usulan desain $\mathrm{TAB}$ yang memiliki sudut pantulan lebar dan halus. Model (a) dan (d) pada Gambar 2 memperlihatkan konsep tabung silinder, sedangkan (b) dan (c) menggunakan konsep tabung berbentuk bola.

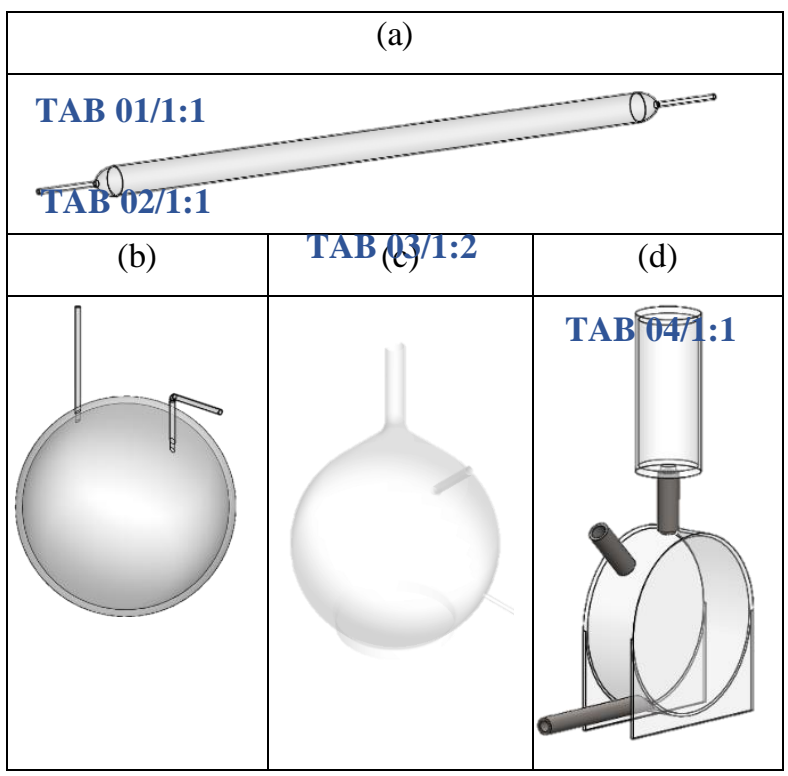

Gambar 2. Usulan desain tabung aerosol bertekanan.

Penamaan model TAB 01/1:1 pada penelititan ini diartikan sebagai model TAB 01 dengan konfigurasi diameter inlet/outlet sebesar 1:1. Hasil yang diharapkan yaitu terpilihnya satu 
diantara empat model dengan kriteria memiliki beda tekanan yang rendah dengan laju aliran luaran yang tinggi.

\section{METODOLOGI}

Perangkat lunak CFD yang digunakan sebagai perangkat utama penelitian terdiri dari GAMBIT versi 2.3.16 dan FLUENT 6.3. Perangkat lunak GAMBIT versi 2.3.16 digunakan sebagai pembuat model dan implementasi solver terhadap kondisi batas secara berurutan, sedangkan FLUENT 6.3. digunakan untuk komputasi numerik dan analisis grafis (postprocessing). Tahapan penelitian ini ditampilkan pada Gambar 3 melalui diagram alir.

Pada alur pembuatan setiap model sesuai Gambar 3, skema mesh yang digunakan sebagian besar yaitu tetrahedral. Pemodelan dan simulasi CFD menggunakan metode elemen hingga, yaitu dengan memecah orde elemen/volume model menjadi lebih kecil (sel). Sel-sel ini mewakili parameter fisis dalam suatu volume model 3D. Data geometri usulan desain model yang dipaparkan pada Gambar 2 kolom (a), (b), (c), dan (d) diberikan oleh Tabel 1 berikut;

Tabel 1. Data empat model geometri TAB.

\begin{tabular}{ccc}
\hline Model & Volume fluida $\left(\mathrm{m}^{3}\right)$ & Total Mesh \\
\hline TAB 01 & $1,285 \times 10^{-3}$ & $\pm 2,2 \times 10^{5}$ \\
TAB 02 & $4,406 \times 10^{-3}$ & $\pm 1,4 \times 10^{6}$ \\
TAB 03 & $1,462 \times 10^{-2}$ & $\pm 6,5 \times 10^{5}$
\end{tabular}

ТAB $04 \quad 7,275 \times 10^{-3} \pm 2,7 \times 10^{5}$

Tabel 1 memberikan gambaran total mesh sesuai dengan bentuk geometri model. Skema mesh yang dibuat pada model TAB 01 berbeda dengan lainnya. Model tersebut memiliki bentuk simetrik dengan karakteristik meshing berpola. Sehingga skema mesh copper dapat digunakan khusus pada model TAB 01 . 


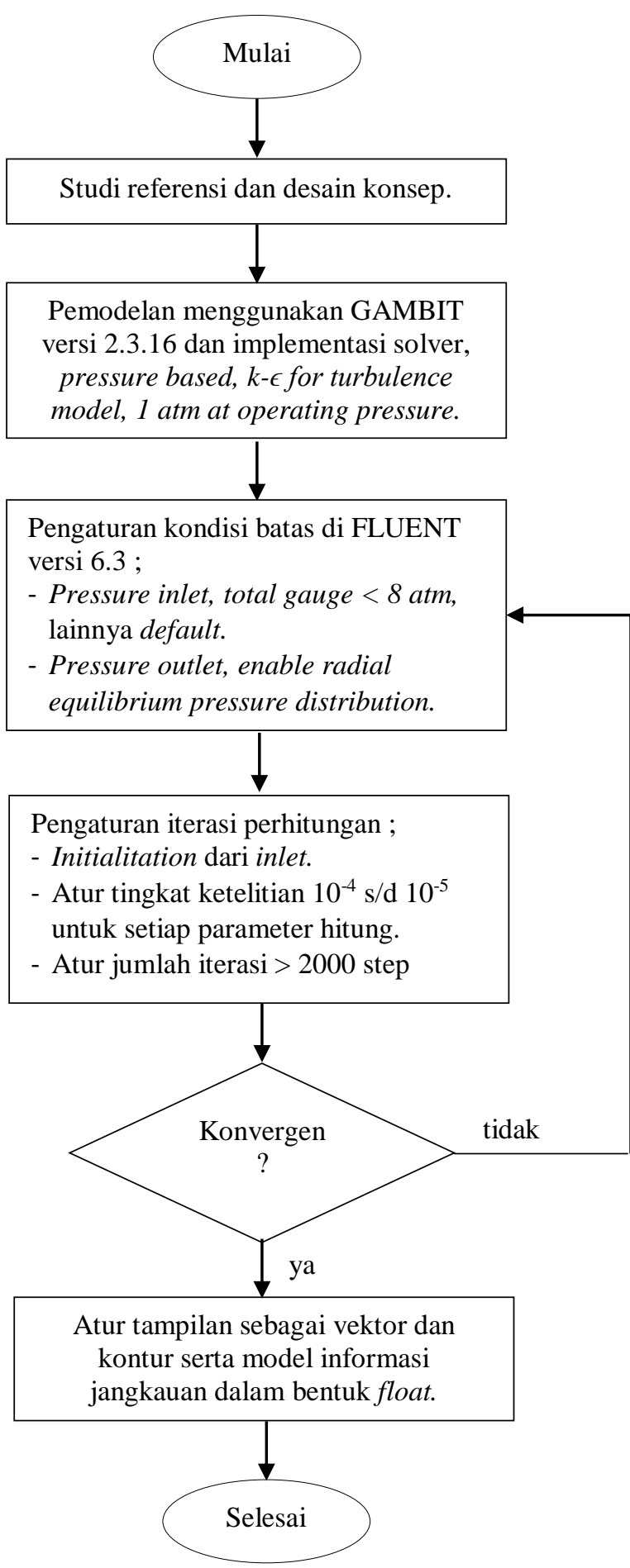

Gambar 3. Diagram alir pemodelan dan simulasi menggunakan FLUENT versi 6.3.

Setelah model diberi inisiasi FLUENT 5/6 sebagai solver dan kondisi batas pada face dan volume melalui perangkat lunak GAMBIT versi 2.3.16, kemudian di-export dalam bentuk 3D dalam format .msh. Pemanggilan file .msh dilakukan menggunakan FLUENT versi 6.3. Sebelum nilai-nilai diimplementasikan ke dalam model solver, penyesuaian dimensi dan parameter unit dilakukan. Untuk meminimalisir kesalahan hitung dan mengoptimalkan keandalan simulasi pra validasi eksperimen, fungsi SIMPLE pada pressure-velocity coupling serta model discretization iteration menggunakan second order dengan tingkat ketelitian hitung $10^{-4}$ s/d $10^{-5}$ per iteration.

Setelah konvergensi perhitungan tercapai, pola dinamika fluida dapat dianalisis dalam bentuk distribusi vektor dan kontur. Analisis terhadap bentuk vektor dan kontur direkomendasikan untuk laju aliran dan parameter termal/tekanan secara berurutan. Tampilan vektor memiliki informasi arah aliran dan besarnya dalam bentuk grafis sesuai dengan tingkatan tertentu sehingga mampu mencitrakan dinamika fluida yang ada dalam lapisan dinding. Setelah satu kali perhitungan selesai pada kondisi pressure inlet 2 atm, variasi tekanan statik inlet dilanjutkan sampai 7 atm. Adapun rentang nilai pressure inlet diberikan sesuai spesifikasi yang dimiliki kompresor.

\section{HASIL DAN PEMBAHASAN}

Telah dilakukan perhitungan pada enam jenis variasi tekanan terhadap empat variasi model TAB. Tabel 2 memaparkan perbandingan nilai tekanan total dan laju alir 
pada posisi inlet - outlet setiap model yang

warna.

dilengkapi dengan informasi bargraph dan

Tabel 2. Profil dinamika fluida setiap model TAB

\begin{tabular}{|c|c|c|c|c|c|c|c|}
\hline \multirow{2}{*}{ Model } & \multicolumn{2}{|c|}{ In } & \multicolumn{2}{|c|}{ Out } & \multicolumn{2}{|c|}{ Perbedaan In-Out } & \multirow{2}{*}{$\begin{array}{c}\text { Pstatic } \\
\text { (atm) }\end{array}$} \\
\hline & $v$ & Ptotal & $v$ & Ptotal & $d v$ & $d P$ & \\
\hline \multirow{6}{*}{ ТАВ 01} & 282.5 & 3.01 & 282.5 & 1.46 & 0 & 1.55 & 2 \\
\hline & 346.28 & 4.02 & 334.34 & 1.45 & 11.94 & 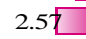 & 3 \\
\hline & 397.53 & 5.01 & 383.83 & 2.01 & 13.7 & $3 \square$ & 4 \\
\hline & 448.05 & 6.03 & 432.61 & 2.37 & 15.44 & 3.66 & 5 \\
\hline & 489.24 & 7.03 & 472.37 & 2.37 & 16.87 & 4.66 & 6 \\
\hline & 531.68 & 8.04 & 513.35 & 2.75 & 18.33 & 5.29 & 7 \\
\hline \multirow{6}{*}{ ТАВ 02} & 216.58 & 2.95 & 216.58 & 1.31 & 0 & 1.64 & 2 \\
\hline & 265.9 & 3.93 & 265.9 & 1.46 & o & $2 . 4 \longdiv { \swarrow }$ & 3 \\
\hline & 306.16 & 4.9 & 306.16 & 1.61 & o & 3.29 & 4 \\
\hline & 343.33 & 5.87 & 343.33 & 1.76 & 0 & 4.11 & 5 \\
\hline & 394.9 & 6.85 & 394.9 & 1.89 & o & 4.96 & 6 \\
\hline & 407.28 & 7.82 & 407.28 & 2.05 & o & 5.77 & 7 \\
\hline \multirow{6}{*}{ ТАВ 03} & 447.28 & 2.95 & 12.09 & 1.02 & 435.19 & 1.93 & 2 \\
\hline & 545.62 & 3.93 & 14.75 & 1.06 & 530.87 & 2.87 & 3 \\
\hline & 636.46 & 4.9 & 17.2 & 1.03 & 619.26 & 3.87 & 4 \\
\hline & 711.37 & 5.88 & 19.23 & 1.08 & 692.14 & 4.8 & 5 \\
\hline & 783.18 & 6.85 & 21.17 & 1.08 & 762.01 & 5.77 & 6 \\
\hline & 848.19 & 7.83 & 22.93 & 1.1 & 825.26 & 6.73 & 7 \\
\hline \multirow{6}{*}{ TAB 04} & 308.29 & 2.94 & 319.7 & 1.65 & -11.41 & 1.29 & 2 \\
\hline & 384.34 & 3.93 & 396.74 & 1.97 & -12.4 & 1.96 & 3 \\
\hline & 467.49 & 4.88 & 486.16 & 2.52 & -18.67 & 2.36 & 4 \\
\hline & 531.36 & 5.85 & 552.58 & 2.86 & -21.22 & 2.99 & 5 \\
\hline & 557.71 & 6.81 & 600.79 & 3.25 & -43.08 & 3.56 & 6 \\
\hline & 628.76 & 7.78 & 653.88 & 4.07 & -25.12 & 371 & 7 \\
\hline
\end{tabular}

Berdasarkan Tabel 2., perbedaan laju alir berbentuk bola yang kemudian ditambah $(d v)$ dan tekanan $(d P)$ pada desain TAB 03 terlihat berbeda daripada model lain. Hal ini mengacu pada bentuk geometri TAB 03 di mana memiliki diameter inlet yang lebih kecil daripada outlet sebesar 1:2. Sementara itu, TAB 04 dengan konfigurasi desain inlet/outlet sebesar 1:1 memiliki nilai rerata $d v$ dan $d P$ yang lebih kecil dari semua model yaitu $-21.98 \mathrm{~m} / \mathrm{s}$ dan 2,65 atm secara berurutan. Nilai minus (-) mengindikasikan adanya peningkatan besarnya nilai laju aliran. Keunikan terjadi pada model TAB 02 dengan nilai $d v$ yang tetap namun memiliki $d P$ yang lebih besar dari TAB 04 yaitu sebesar 3.71 atm. Besarnya nilai $d P$ ini diperoleh dari adanya perbedaan luas permukaan aliran inlet terhadap ruang dengan panjang geometri pipa luaran bersiku. Perbedaan luasan TAB 01, yang memiliki nilai rerata $d P$ yaitu sebesar 3,46 atm, yaitu lebih kecil dari TAB 02 sebesar 3,70 atm, namun memiliki nilai $d v$ sebesar $12,71 \mathrm{~m} / \mathrm{s}$ (lebih besar dari TAB 02) .

Nilai $d v$ dan $d P$ masing-masing model dapat dilihat pada Tabel 2. Nilai tersebut menunjukkan ada korelasi terhadap bentuk geometrinya dalam menentukan suatu dinamika fluida tanpa melibatkan tenaga dari luar seperti motor listrik. Berikut beberapa hasil simulasi CFD yang ditampilkan pada Gambar 4, Gambar 5, Gambar 6, dan Gambar 7 untuk TAB 01, TAB 02, TAB 03, dan TAB 04 secara berturut - turut. Pola aliran fluida masing- 


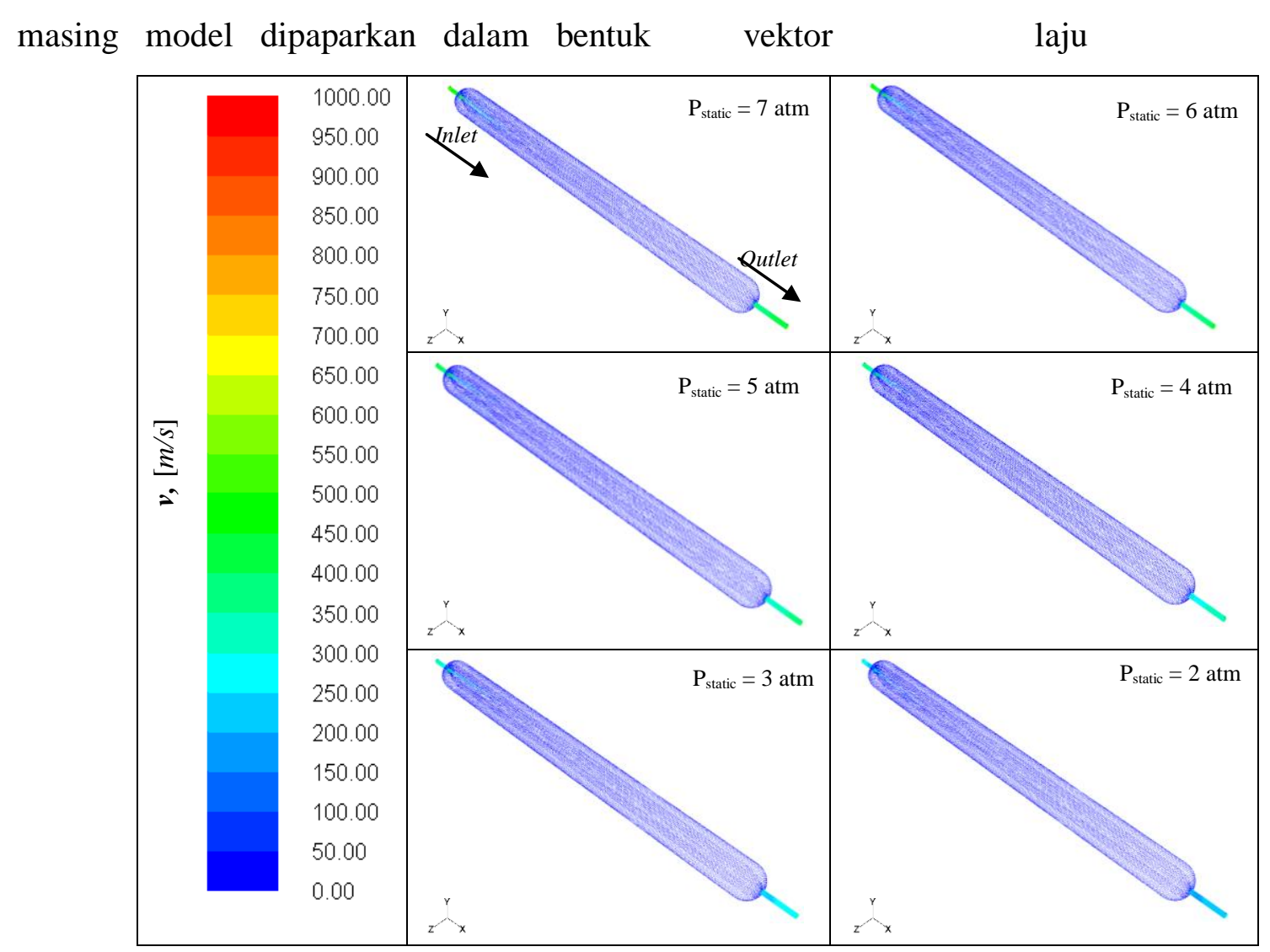

Gambar 4. Profil fluida pada beberapa variasi tekanan inlet TAB 01.

Profil TAB 01 memiliki dimensi panjang ke arah sumbu $x$ sebesar $743 \mathrm{~mm}$. Desain memanjang ini memiliki $d P$ yang besar. Warna biru menunjukkan rendahnya laju udara setelah melewati inlet. Namun, akibat adanya perubahan luas penampang outlet yang mengecil, terjadi perubahan pertambahan laju aliran sekitar 4 kali lipat dari laju aliran di dalam TAB 01, sehingga $d v$ di inlet dan outlet tidak besar. Dinamika fluida yang terjadi di dalamnya tidak menunjukkan adanya pusaran udara akibat tekanan inlet yang memungkinkan untuk terjadinya pencampuran material ringan di sepanjang ruang $\mathrm{TAB} 01$.

Selanjutnya, pada Gambar 5 ditampilkan profil dinamika fluida TAB 02 . TAB 02 memiliki diameter tabung sebesar $281 \mathrm{~mm}$ dengan panjang pipa inlet sekitar $200 \mathrm{~mm}$ mengarah vertikal. Bagian outlet berbentuk sudut menyiku dengan posisi pipa keluaran horizontal. Hubungan geometri TAB 02 terhadap dinamika fluida yang terjadi tidak berbeda jauh dengan TAB 01 . 


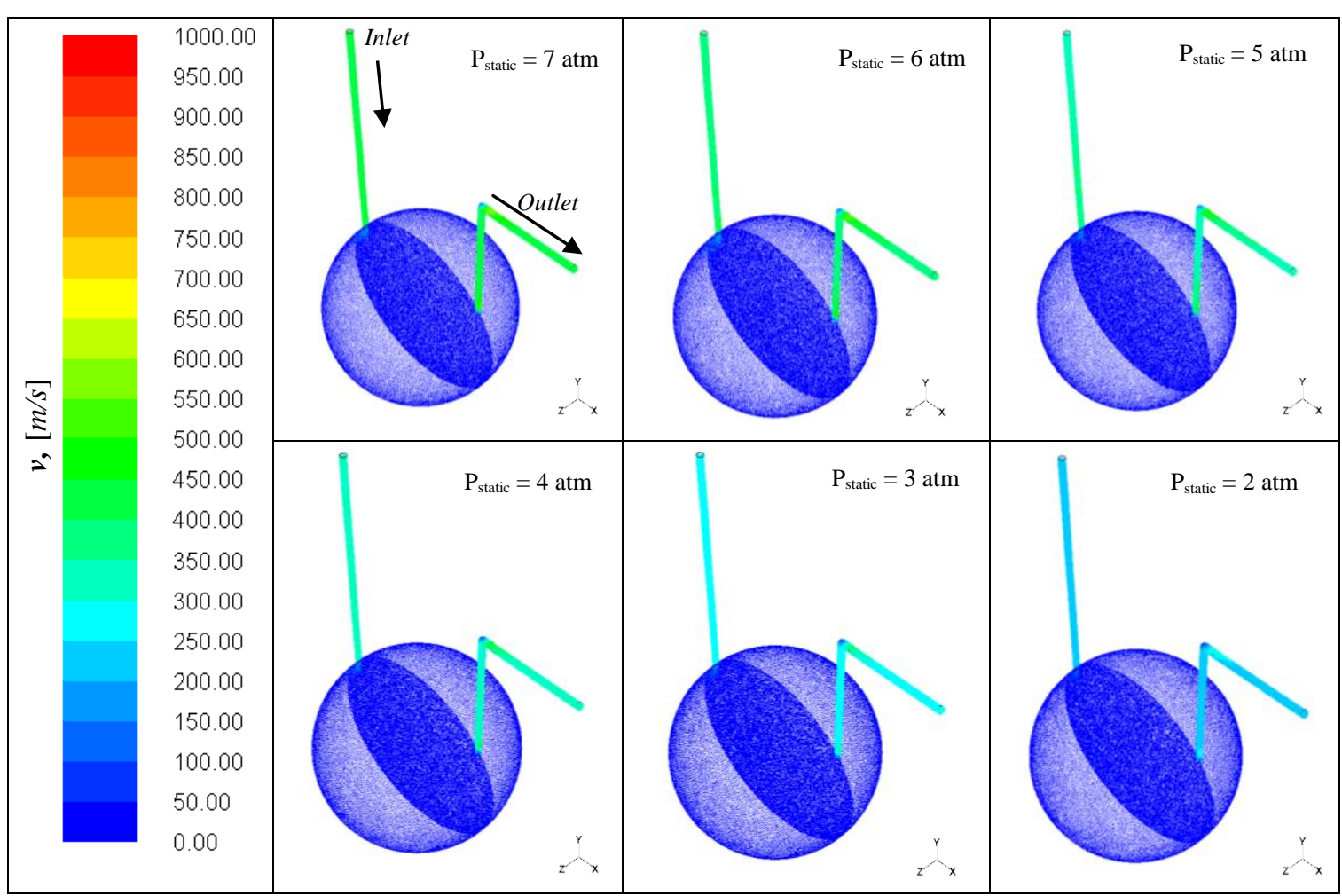

Gambar 5. Profil fluida pada beberapa variasi tekanan inlet TAB 02.

Profil laju aliran rerata di dalam ruang setelah melewati pipa berdiameter $6,35 \mathrm{~mm}$ ( $1 / 4$ in) menurun sebanyak 2,4 kali lipatnya dan kembali meningkat saat terjadi perubahan geometri outlet. Perbedaan yang mencolok terlihat pada kemampuan ruang berbentuk bola untuk menghasilkan pusaran udara terhadap tekanan inlet sehingga dapat mengoptimalkan pergerakan aerosol dan meminimalisir terjadinya pengendapannya. Aerosol ini kemudian diarahkan untuk keluar melalui outlet bersiku yang tentunya memiliki kontribusi peningkatan $d P$ yang signifikan.

Pada Gambar 6, profil dinamika fluida model TAB 03 diidentifikasi memiliki kemampuan pembangkitan pusaran udara seperti TAB 02 namun dengan posisi inlet horizontal. Pertimbangan penempatan posisi inlet ini dilakukan agar aerosol dari sistem injeksi ke FESPeCo Mod.1 dapat disalurkan secara homogen (meminimalisir endapan akibat kehilangan tekanan operasi). TAB 03 memiliki dimensi tabung bola sebesar 300 $\mathrm{mm}$ dengan panjang corong sampai $500 \mathrm{~mm}$. 


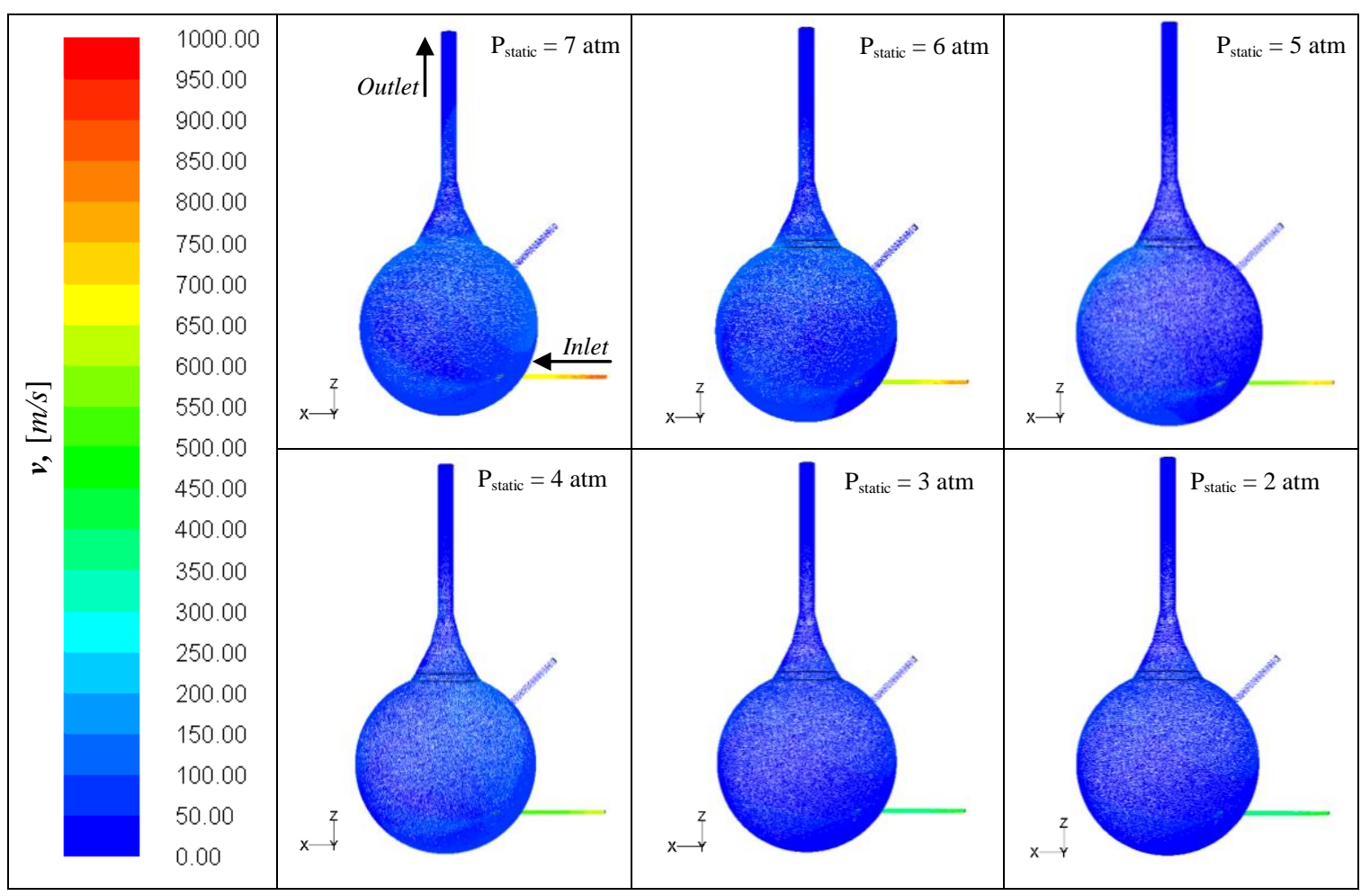

Gambar 6. Profil fluida pada beberapa variasi tekanan inlet TAB 03.

Selain variasi posisi inlet, TAB 03 memiliki variasi diameter inlet dan outlet yang berbeda terhadap TAB 01 dan TAB 02 . Gambar 6 menunjukkan terjadinya pola yang sama terhadap TAB 02 namun dengan nilai $d P$ tinggi secara homogen di sepanjang ruang $\mathrm{TAB}$ 03. Posisi inlet $\mathrm{TAB} 03$ berada pada titik $75 \mathrm{~mm}$ dari titik tengah bola sehingga fenomena pusaran udara dapat dibentuk dengan memberikan tekanan operasi. Besarnya penurunan laju aliran yang melalui pipa inlet berdiameter $6,35 \mathrm{~mm}(1 / 4$ in) ke dalam ruang bola $\mathrm{TAB} 03$ sekitar 4,3 kali lipat dari laju aliran inlet dan merata disepanjang ruang sampai outlet. Perubahan pola laju aliran ini erat kaitannya dengan perubahan tekanan operasinya. Adanya perbedaan luas penampang inlet dan outlet pada fluida kerja yang memiliki sifat compressible flow memungkinkan terjadi perubahan tekanan yang besar.

Sementara itu, profil dinamika fluida model lainnya ditampilkan pada Gambar 7. TAB 04 merupakan gabungan konstruksi TAB 01, TAB 02, dan TAB 03 atas pertimbangan desain dinamika fluidanya. TAB 04 memiliki tabung berbentuk disk dengan diameter $300 \mathrm{~mm}$ dan pipa inlet/outlet sekitar $100 \mathrm{~mm}$ sampai $200 \mathrm{~mm}$. Desain geometri disk mempertimbangkan fenomena pembentukan pusaran udara, yaitu dengan memberikan tekanan operasi pada jarak $75 \mathrm{~mm}$ dari titik tengah diameter tabung. Besarnya penurunan laju aliran yang melalui pipa inlet berdiameter 1 in ke volume ruang TAB 04 tidak lebih dari 2 kali lipat laju aliran mula - mula inlet. Sedangkan di sisi outlet TAB 03 
peningkatan laju aliran rerata terjadi sebesar

hampir 2 kali lipat dari laju aliran di dalam

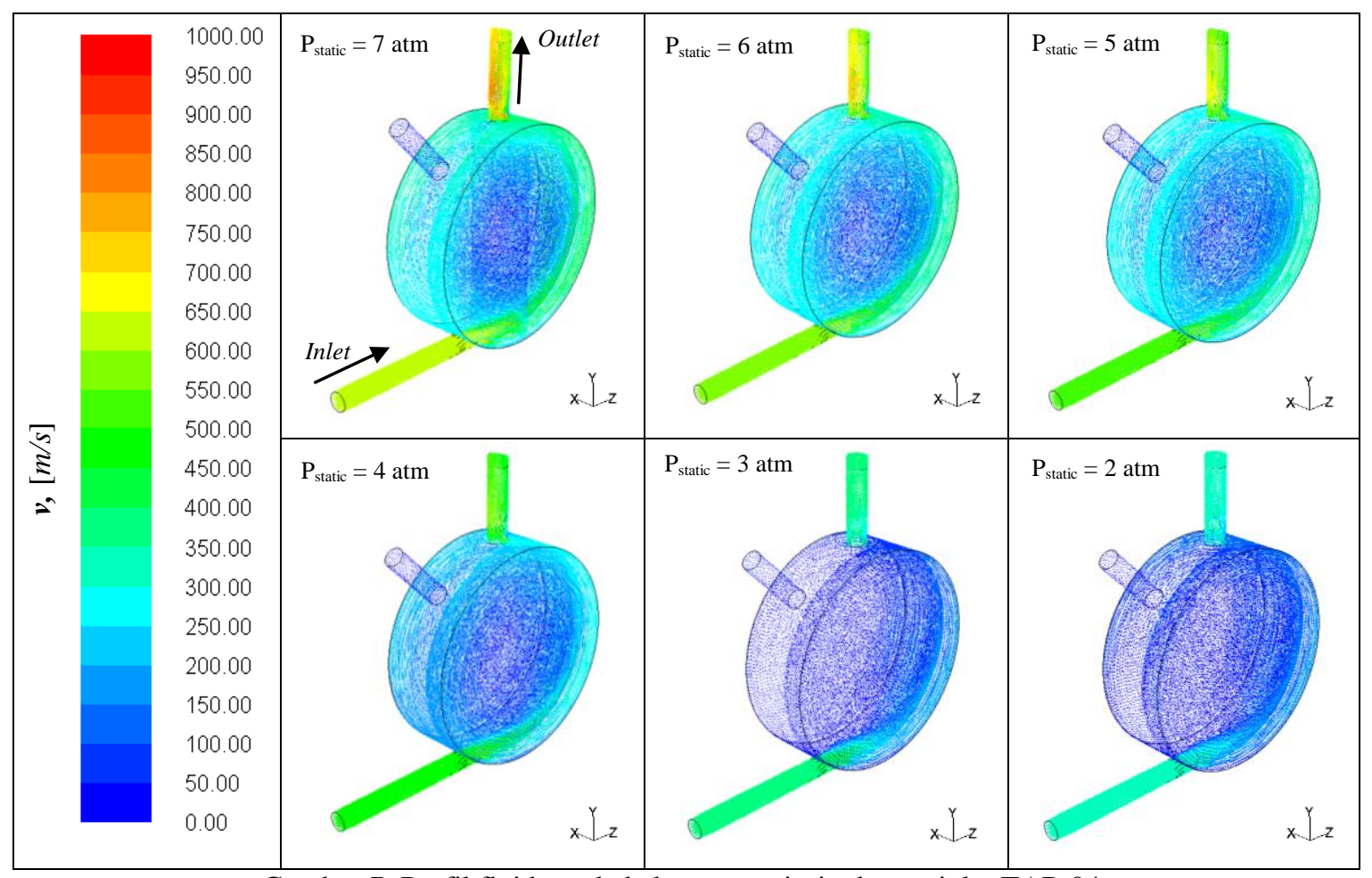

Gambar 7. Profil fluida pada beberapa variasi tekanan inlet TAB 04.

Ini menunjukkan bahwa potensi aerosol terbawa aliran udara semakin besar dan diharapkan mampu meniadakan potensi endapan di dalam ruang TAB 04.

\section{KESIMPULAN}

Penelitian pendahuluan untuk penentuan model tabung aerosol bertekanan telah dilakukan pada empat desain yang menggunakan fluida kerja berupa udara, yaitu TAB 01, TAB 02, TAB 03, dan TAB 04. Berdasarkan hasil simulasi CFD, model TAB 04 memiliki kemampuan pembangkitan pusaran udara yang lebih baik dari model lainnya, yaitu dibuktikan dengan adanya peningkatan besarnya nilai laju aliran udara di outlet terhadap inlet, yang berbeda dari ketiga model lainnya. Oleh karena itu model TAB 04 direkomendasikan untuk selanjutnya dapat dilakukan proses fabrikasi.

\section{UCAPAN TERIMAKASIH}

Penulis mengucapkan terima kasih atas dukungan dan pembiayaan dari KAK PLTN, Pusat Teknologi dan Keselamatan Reaktor Nuklir Badan Tenaga Nuklir Nasional dalam penelitian ini. 
DAFTAR PUSTAKA

1. F. SULAIMAN, "Identifikasi Potensi, Dampak, dan Pengendalian Lingkungan Dalam Pengembangan Pembangkit Listrik Tenaga Nuklir," Vol. 2 No. 3, no. DEDIKASI, p. 27, 2011.

2. I. KLJENAK AND B. MAVKO, "Simulation of KAEVER Experiments on Aerosol Behavior in a Nuclear Power Plant Containment at Accident Conditions with the ASTEC Code," Proc. Int. Conf. Nucl. Energy New Eur. 2006, 2006.

3. Y. OKI, et.all, "Size Measurement of Radioactive Aerosol Particles in Intense Radiation Fields Using Wire Screens and Imaging Plates," $J$. Radiat. Prot. Reasearch 2016, vol. 41, no. 3, pp. 216-221, 2016.

4. MARTIN ROBERTand FREPOLI CESARE, "Design Basis Accident Analysis Methods for Light-Water Nuclear Power Plants," 2019. [Online]. Available: https://books.google.co.id/books?hl=i $\mathrm{d} \& \mathrm{lr}=\& \mathrm{id}=9$ AmMDwAAQBAJ \&oi $=\mathrm{f}$ $\mathrm{nd} \& \mathrm{pg}=\mathrm{PR} 5 \& \mathrm{dq}=$ mitigation + system + on+radiactive+release $+b y+$ spray $+p$ wr\&ots $=$ hn6qNEMr0\&sig $=$ YEDwvX 7ARLCu31Igp5gEAG3F5-Y\&redir_ $\mathrm{esc}=\mathrm{y} \# \mathrm{v}=$ onepage $\& \mathrm{q}=$ spray $\& \mathrm{f}=\mathrm{false}$.

5. K. SANTOSA, "Pengembangan Sistem Akuisisi DataTekanan dan Temperatur pada FESPeCo Menggunakan Ni cRIO 9074," Vol. 17, No. 2, pp. 79-87, 2013.

6. G. B. HERU, "Pemrograman Sistem Akuisisi Data Pengukuran pada Fasilitas Eksperimen untuk Simulasi Pendinginan Containment," Sigma Epsil., vol. 18, no. 2, pp. 51-57, 2014.

7. P. GERALDINI, "Validation of a CFD Study of Particle Distribution in Nuclear Workplace," Proc. 2016
COMSOL Conf. Munich, 2016.

8. A. K. DWIVEDI et al., "Aerosol depositional characteristics in piping assembly under varying fl ow conditions," Prog. Nucl. Energy, vol. 116, no. April, pp. 148-157, 2019.

9. ANSYS, "7.3.3 Pressure Inlet Boundary Conditions." [Online]. Available:

http://www.afs.enea.it/project/neptuni us/docs/fluent/html/ug/node239.htm\# sec-pinlet-hydrostatic. 